\title{
Momentum and the Disposition Effect: The Role of Individual Investors
}

\author{
Jungshik Hur, Mahesh Pritamani, and Vivek Sharma*
}

\begin{abstract}
We hypothesize that disposition effect-induced momentum documented in Grinblatt and Han (2005) should be stronger in stocks with greater individual investors' presence since individual investors are more prone to the disposition effect. We find strong evidence for our hypothesis for a large sample of NYSE/AMEX/NASDAQ stocks from the end of 1980 to 2005. Our results hold across different momentum strategies using alternative ways of defining individual investors' presence in a stock and maintain even after controlling for variables known to drive momentum. Furthermore, we find that our results are stronger for hard-to-value stocks consistent with the findings of Kumar (2009).
\end{abstract}

Stock price momentum is a robust anomaly present in stocks of all market capitalizations, has been documented in several markets across the world, and continues unabated since its discovery by Jegadeesh and Titman (1993). Jegadeesh and Titman (2001), using more recent time periods, confirm that the momentum strategy is profitable out-of-sample and is not the result of data mining. Haugen and Baker (1996) and Rouwenhorst (1998) find momentum strategies to be profitable for a number of international markets. Fama and French (2008) designate this as the center stage anomaly of recent years. ${ }^{1}$ While various risk-based explanations of momentum have been proposed by researchers over the years, most of the recent papers point to some sort of behavioral bias on the part of investors as a possible source of this anomaly. ${ }^{2}$ In one set of studies, momentum occurs due to continued overreaction of investors (DeLong et al., 1990; Daniel, Hirshleifer, and Subrahmanyam, 1998; Lewellen, 2002). In the other set of studies, momentum occurs due to underreaction to news (Chan, Jegadeesh, and Lakonishok, 1996; Barberis, Shleifer, and Vishny, 1998; Hong and Stein, 1999; Chen and Hong, 2002).

We are grateful to Bill Christie (the editor) and special thanks are due to an anonymous referee for many constructive and illuminating comments and suggestions, which immensely helped us improve the paper. We also thank Susan Ji (the discussant) and other participants at FMA 2008 meeting at Dallas for helpful comments. Jungshik Hur and Vivek Sharma would like to acknowledge the financial support from their respective universities for the study. We are responsible for any errors.

* Jungshik Hur is an Assistant Professor in the Department of Economics and Finance at Louisiana Tech in Ruston, LA. Mahesh Pritamani is a Senior Research Analyst with Russell Investments in Tacoma, WA. Vivek Sharma is an Assistant Professor in the Department of Accounting and Finance at the University of Michigan-Dearborn in Dearborn, MI.

\footnotetext{
${ }^{1}$ Jegadeesh and Titman (2005) review the momentum literature and conclude “... momentum effect is quite pervasive and very unlikely to be explained by risk."

${ }^{2}$ Conrad and Kaul (1998) were the first to argue that momentum profits reflect compensation for risk and are driven by cross-sectional differences in expected returns. Other studies offering risk as an explanation for momentum include Agarwal and Taffler (2008), Berk, Green, and Naik (1999), Chordia and Shivakumar (2002), Cochrane (1996), Johnson (2002), and Liu and Zhang (2008). However, Fama and French (1996), Jegadeesh and Titman (2001), and Grundy and Martin (2001) demonstrate that risk-based explanations cannot account for all the profits of momentum strategies.
} 
Recent research has explored yet another explanation for momentum in stock returns rising out of another behavioral bias of investors. It is the tendency of investors to hold on to losing stocks for too long and sell winning stocks too soon, a widely documented regularity in experimental and financial markets in many countries. In an influential paper, Shefrin and Statman (1985) label this phenomenon as the disposition effect. A combination of prospect theory (Kahneman and Tversky, 1979) and mental accounting (Thaler, 1980) are advanced as plausible explanations for the disposition effect. Grinblatt and Han (2005) and Frazzini (2006) note that the disposition effect should lead to underreaction to news and momentum in stock returns for which they find supporting empirical evidence. Grinblatt and Han (2005) find that a variable proxying for aggregate unrealized capital gains (or capital gains overhang) is the primary driver of momentum, and past returns do not predict future returns after controlling for this variable. In a related study, Frazzini (2006), using different variables to proxy for aggregate unrealized capital gains, finds that stocks with high capital gains overhang underreact to positive news and display strong positive abnormal returns in subsequent periods while stocks with high capital losses underreact to negative news and display strong negative abnormal returns in subsequent periods. In summary, Grinblatt and Han (2005) and Frazzini (2006) add another interesting explanation for momentum in stock returns based on the disposition effect.

Much of the asset pricing literature categorizes investors into two types: 1) informed and 2) uninformed. It is also widely accepted that institutional investors are generally more informed than individual investors. Many papers also argue that individual investors are more prone to behavioral biases including the disposition effect. ${ }^{3}$ The first and one of the most prominent studies in this line of research is Odean (1998) who finds that individual investors hold losing investments for too long and sell winning investments too soon. Odean (1999), Barber and Odean (2000, 2001, 2002), Grinblatt and Keloharju (2001), Brown et al. (2006), and Dhar and Zhou (2006) provide additional evidence that individual investors are more prone to the disposition effect. Indirect support also comes from Cici (2005) and Xu (2007) who find little evidence of the disposition effect by mutual funds. Thus, the extant literature indicates that greater investor sophistication is positively correlated to less susceptibility to the disposition effect. ${ }^{4}$

In this paper, we make an attempt to link the above two streams of literature regarding disposition effect-induced momentum and the disposition effect's predominance as an individual investor phenomenon. In other words, this study helps us to explain the role of individual investors in disposition effect-induced momentum. Our study is also indirectly related to more recent studies documenting that trading by individual investors has implications for a cross-section of stock returns (Hvidkjaer, 2008; Barber, Odean, and Zhu, 2009). Specifically, we hypothesize that if the disposition effect results in momentum in stocks, then the ability of the disposition effect to explain future returns should be positively related to the fraction of the investor population in each stock that are subject to this effect. Since the aforementioned evidence suggests that individual investors are more likely to suffer from this effect, it follows that the disposition effect will have greater explanatory power to predict momentum for stocks that are associated with greater individual investors' presence.

To proxy the disposition effect, we use the Grinblatt and Han (2005) measure for unrealized capital gains (losses) based on past prices and share turnover. In contrast to Grinblatt and Han (2005) who use the total share turnover, we use share turnover attributable to individual investors to measure the reference price (aggregate cost) faced by individual investors. To proxy individual

\footnotetext{
${ }^{3}$ Other prominent biases affecting individual investors are overconfidence, limited attention, and representativeness.

${ }^{4}$ However, a few studies document the disposition effect's influence on the trading behavior of smart investors (Shapira and Venezia, 2001; Wermers, 2003; Locke and Mann, 2004; Coval and Shumway, 2005).
} 
investors' presence in stocks, we use two measures. As a first measure, we use the fraction of shares outstanding in each stock that are not owned by large institutional investors. This indirectly measures the individual investors' presence in each stock. Our second measure is based on the fraction of trading volume in each stock by individual investors. We test our hypothesis on the following [ranking period, holding period] momentum strategies: $[1,3],[3,3]$, and $[6,6]$. The $[3,3]$ and $[6,6]$ momentum strategies have been widely studied based on the initial results by Jegadeesh and Titman (1993). The motivation for the [1,3] strategy comes from a recent work by Gutierrez and Kelly (2008) who find that momentum strategies based on past week to past month ranking periods are profitable as long as the holding periods are sufficiently long in length. We examine average portfolio returns to $3 \times 3 \times 3$ portfolios formed on past returns, capital gains overhang, and our measures of individual investors' presence in stocks. We find that within each past return group, the high minus low capital gains overhang portfolio earns greater positive returns the higher our measures of individual investors' presence in stocks. This is consistent with our hypothesis that the disposition effect is a better predictor of future returns in stocks with higher individual investors' presence that have a greater tendency for the disposition effect.

As a robustness check, we test and find that our results hold even if we base our measure of individual investors' presence in stocks on residual institutional ownership instead of raw institutional ownership to control for the fact that characteristics (such as size, book-to-market, past returns, analyst coverage) related to institutional ownership could be driving the results. Our results are also robust to using different proxies to identify the fraction of individual investors' trading volume. In addition, we use Fama-MacBeth (1973) regressions to test our hypothesis and conclude that the results continue to hold. Specifically, we find that the future return is positively related to the interaction variable (capital gains overhang $\times$ measures of individual investors' presence in stocks), suggesting that the ability of capital gains overhang to predict future returns is increasing in individual investors' presence in stocks. Our results are robust to excluding NASDAQ stocks from our sample. Last, we find that individual investors induced disposition effect has greater explanatory power for predicting future returns of hard-to-value stocks.

In summary, we make a contribution to the literature by extending and refining Grinblatt and Han (2005) concerning the role of the disposition effect when explaining momentum in stock prices. Our analysis indicates that since the disposition effect is primarily an individual investor behavioral bias, the ability of this effect to explain momentum is positively correlated to the presence of individual investors in stocks.

The remainder of the paper is organized as follows. Section I describes the data and methodology used in the paper. Section II documents the results based on calendar-time portfolio average returns to sorted portfolios and based on Fama-MacBeth (1973) regressions. Section III provides our conclusions.

\section{Data and Methodology}

\section{A. Sample and Individual Investor Measures}

In order to compute a measure for unrealized capital gains (losses), we first extract data of all common stocks (with Share Code 10 or 11) of the NYSE/AMEX/NASDAQ with price and volume information on CRSP daily files from 1984 to 2005 that intersects with Institute for the Study of Security Markets (ISSM) and Trades and Quotes (TAQ) files. The choice of share code 10 or 11 essentially removes all American Depository Receipts (ADRs), Shares of Beneficial Interest (SBIs), Units, Real Estate Investment Trusts (REITS), closed-end funds, and companies incorporated outside the United States. Our choice of 1984 as starting point is dictated by the 
following. First, intraday data used in the study come from ISSM and TAQ files. We have access to ISSM data beginning in 1984 and TAQ data starting in 1993. We use ISSM data until 1992 and TAQ data from 1993 to 2005 . Second, institutional holding data, our first proxy for individual ownership, begins in 1980 .

Thus, our initial sample of common stocks comes from the intersection of ISSM, TAQ, and CRSP daily files from 1984 to 2005 . For convenience sake, we call our measure of unrealized capital gains (losses) capital gains overhang. Following Grinblatt and Han (2005), we compute reference price (cost basis), $R P_{t}$, for each stock at the end of every month from the end of 1986-2005 using up to three years of daily data. ${ }^{5}$ Our estimate of reference price is as follows:

$$
R P_{t}=\frac{1}{k} \sum_{n=1}^{T}\left(V_{t-n} \prod_{\tau=1}^{n-1}\left[1-V_{t-n+\tau}\right]\right) P_{t-n},
$$

where $V_{t}$ is date $t$ 's turnover in the stock. $T$ refers to the number of trading days in the previous three years with available daily price and volume information.

Grinblatt and Han (2005) implicitly assume that all investors are equally subject to the disposition effect and, as such, use total turnover (total trading volume/number of shares outstanding) in computing the reference price. However, the main innovation of our paper is that the disposition effect is primarily an individual investor phenomenon; therefore, we need to modify their measure to focus on the reference price faced by individual investors. In order to do so, we replace the total turnover in the Grinblatt and Han (2005) measure with share turnover attributed to individual investors. ${ }^{6}$

To approximate individual investors' turnover, we use small-sized trades for each stock on each day of trading. We follow Barber, Odean, and Zhu (2009), Malmendier and Shantikumar (2007), Lee (1992), and Hvidkjaer (2008) as well as others and use the dollar amount of trade size to determine if the trade is initiated by individual investors. In particular, we assume that trades that are less than or equal to $\$ 10,000$ in value belong to individual investors. ${ }^{7}$ We use the total trading volume for all such trades to proxy for turnover attributed to individual investors. The term in parentheses multiplying $P_{t-n}$ is weights, and $k$ is a constant that forces the entire weights sum to one. The weight on $P_{t-n}$ reflects the probability that the shares purchased on date $t-n$ have not been traded since. Our proxy for capital gains overhang for each stock at the end of each month $t$ is

$$
g_{t}=\frac{P_{t}-R P_{t}}{P_{t}}
$$

where $P_{t}$ is the price of the stock at the end of month $t$. We make appropriate adjustments for stock splits and stock dividends in share turnover and share price variables while computing $R P_{t}$ and $g_{t}$. Thus, we have the capital gains overhang variable for each stock at the end of every month for the period from 1986 to 2005 .

\footnotetext{
${ }^{5}$ Use of $T=3$ years, though somewhat arbitrary, recognizes the fact that longer time periods are not useful as distant market prices have little effect on the reference price. It also gives us an accurate measure of unrealized capital gains (losses). Moreover, Grinblatt and Han (2005) demonstrate that the ability of capital gains overhang to predict future returns is insensitive to using three, five, or seven years of past returns and volume data.

${ }^{6}$ We sincerely thank an anonymous referee for this insight. Our results remain qualitatively similar even when we compute reference price using total turnover.

${ }^{7}$ For robustness, we also used $\$ 5,000$ and $\$ 20,000$ trades to identify individual investors' trades. The results are qualitatively similar to what is reported here with $\$ 10,000$ trades or less. To account for changes in purchasing power, we use the yearly consumer price index to adjust the dollar amount of each trade to the 1984 level.
} 
In the next step, we extract monthly return information for our sample of stocks from CRSP monthly files from 1986 to 2006. Following Jegadeesh and Titman (2001), we exclude stocks with a price less than $\$ 5$ (illiquid stocks) at the time of our computation of momentum/portfolio formation. Similarly, we also delete stocks with a market value less than the lowest size decile of NYSE stocks. Regarding the specific momentum strategies examined, past research, including that of Jegadeesh and Titman (1993) and Rouwenhorst (1998), illustrates that the results of different momentum strategies are quite similar with average returns of approximately $1 \%$ per month when a ranking period of 6,9 , or 12 months is used regardless of the length of the holding period. However, for robustness, we choose three different trading strategies based on the momentum in stock returns. Our first strategy involves forming portfolios by sorting stocks into three groups based on their past six-month buy-and-hold return and holding the portfolio for the subsequent six months. For each stock, the past six-month buy-and-hold return is calculated by compounding the monthly returns. Stocks with missing monthly return data in the ranking period are excluded from the portfolios at the portfolio formation date. We skip a month after forming portfolios to avoid short-term return reversal due to microstructure issues of bid-ask bounce (Jegadeesh, 1990; Lehmann, 1990; Lo and MacKinlay, 1990). For simplification purposes, we term this strategy as $6 \times 6$. Similarly, we formulate $3 \times 3$ and $1 \times 3$ trading strategies.

We use two measures to proxy individual investors' presence in a stock. Our first measure is the fraction of shares not owned by large institutions. This represents shares owned by individual investors. We use Thomson Financial (earlier called CDA Spectrum) 13-F filing data to obtain the quarterly holdings of all institutions for our sample of stocks for the period starting from the fourth quarter of 1986 to the fourth quarter of 2005. To compute aggregate individual ownership in a stock, we first combine the shares held by all institutions at the end of every quarter and divide by the total outstanding shares. This represents the institutional holding in the stock. The aggregate individual investors' presence is simply the remaining fractional ownership. Thus, the higher the institutional holding, the lower is the individual investors' presence and vice versa. We acknowledge that the individual investors' category may include some small institutions and insiders. However, we believe that individual investors hold the largest fraction of shares that are not held by large institutions. Nofsinger and Sias (1999), Dennis and Strickland (2002), and Cohen, Gompers, and Vuolteenaho (2002) also designate shares that are not owned by large institutions as belonging to individual investors. Last, we assume that this measure of individual investors' presence in stock remains constant during the intervening months before the new data become available at the end of next quarter.

Our second measure to proxy individual investors' presence in stocks is based on the fraction of trading volume in each stock that could be attributed to individual investors. ${ }^{8}$ It is inspired by Goetzmann and Massa (2008) who use the ratio of the disposition-motivated trades over the overall trades in the market. We believe that this ratio of individual investors' trading volume over the overall trading volume should be positively correlated with disposition-motivated trades in the stock. Han and Kumar (2009) support this notion by demonstrating that the disposition effect is much stronger among stocks with a high proportion of trading initiated by retail investors. To the extent this new measure is unrelated to our first measure based on institutional holding, it captures a different aspect of individual investors' presence in each stock. To this end, we identify, for each stock in our sample, the trading volume associated with trades of $\$ 10,000$ or less. The total of all such trades constitute the trading volume that could be attributed to individual investors on that day. The fraction of trading attributed to individual investors is simply this trading volume divided by total trading volume on the day of the trading. At the end of each month, we update

\footnotetext{
${ }^{8}$ We thank an anonymous referee for the suggestion that helped us design this measure.
} 
this measure based on the time-series average of daily trading attributed to individual investors over the month.

\section{B. Research Design}

In the first step, we simply examine whether the three momentum strategies were profitable in our sample. To this end, at the end of each month, we sort stocks into three groups on the basis of their past buy-and-hold returns. This is done for $6 \times 6,3 \times 3$, and $1 \times 3$ trading strategies. These stocks in different groups are put together to make three equally weighted portfolios. The portfolio of the highest (lowest) past return stocks is the winning (losing) portfolio. If momentum explains future returns, then we should observe that winning portfolios outperform losing portfolios over the relevant holding period. To measure the future performance of winning/losing portfolios, we examine the average monthly return of the stocks in these portfolios over the relevant holding period after skipping one month between the ranking period and the holding period.

In order to investigate our primary hypothesis as to how the disposition effect-induced momentum in stock returns varies with individual investors' presence in stocks, we use two alternative approaches. In the first method, we study the average returns of portfolios sorted on our computed measures of momentum, capital gains overhang, and our measures of individual investors' presence in stocks for each strategy. For instance, to form the portfolios in our $3 \times 3$ strategy, at the end of each month, we sort the stocks into three groups on the basis of the past three-month buy-and-hold returns. Then, they are further sorted into three groups within each return group on the basis of capital gains overhang measured as of the end of that month. For example, we sort stocks based on past returns January 2000-March 2000 and further sort them based on capital gains overhang as of March 2000 to form portfolios at the end of March 2000. We then skip a month and hold these portfolios from May 2000 to July 2000. This is done to examine the predictive power of capital gains overhang over and above that of past returns. In the next step, we do a three-way sort on the basis of our measures of individual investors' presence in stocks. This helps us investigate if the predictive power of capital gains overhang to explain future returns varies with the degree of the individual investors' presence in the stocks. We conduct both an independent and a dependent sort on our measures of individual investors' presence in stocks and find similar results. For brevity, we report only independent sort results. Thus, we employ $3 \times 3 \times$ 3 sorts on past returns; capital gains overhang, and measure of individual investors' presence in stocks to form portfolios. We adopt a similar procedure in $1 \times 3$ and $3 \times 3$ momentum strategies. To examine whether disposition-induced momentum varies with individual investors' presence in stocks, we study the average return of the portfolio that is long on the highest capital gains overhang stocks and short on the lowest capital gains overhang stocks in each past return group and our measures of individual investors' presence in stocks group. If disposition effect-induced momentum is positively correlated with individual investors' presence in stocks, then we should find increasing average returns to the high minus low capital gain overhang portfolios as the measures of individual investors' presence in stocks increases within each return group.

To compute the average return of the portfolios, we average the monthly portfolio returns using the calendar-time method advocated by Fama (1998), Mitchell and Stafford (2000), and used in Jegadeesh and Titman (1993). For instance, to evaluate the performance of portfolios in $6 \times 6$ strategy, there are six portfolios in Month 6: 1) one formed using returns as of end of Month 6, 2 ) one using returns as of the end of Month 5,3) one using returns as of end of Month 4, and so on. The profit in a month is the equally weighted average of the six overlapping portfolios in that month. 
In our second alternative approach, we examine the effect of individual investors' presence in stocks on disposition effect-induced momentum in monthly cross-sectional Fama-MacBeth (1973) regression. We account for positive autocorrelation in the time-series of coefficient estimates when calculating $p$-values using the Newey-West (1987) technique. Here, we regress the average monthly excess return over the holding period of each stock on past return, our measure of capital gains overhang, and an interaction term given by the cross-product of capital gains overhang and the dummy variable for our measures of individual investors' presence in stocks. We employ monthly excess return by subtracting the return on equally weighted returns on all NYSE/AMEX/NASDAQ stocks from stock's raw return. The use of excess return mitigates the problem associated with missing return for some stocks in future periods. The dummy variable takes the value of $+1,0$, and -1 for high, medium, and low individual investors' presence in the stocks, respectively. If our hypothesis that the dominant part of the disposition effect is confined to stocks with greater individual investors presence, then we expect the coefficient on the interaction term to be positive and statistically significant.

Since our first measure for individual investors' presence in stocks is derived from institutional ownership, it is plausible that our documented results are simply a manifestation of the fact that some firm characteristics that are correlated with institutional ownership are also associated with disposition-induced momentum. The prior literature suggests that institutions have a much stronger demand for larger stocks than for smaller ones (Falkenstein, 1996; Gompers and Metrick, 2001). Similarly, many institutions are momentum traders (Grinblatt, Titman, and Wermers, 1995; Nofsinger and Sias, 1999; Wermers, 1999; Sias, Starks, and Titman, 2006). Gompers and Metrick (2001) and Yan and Zhang (2009) document institutional preference for high book-tomarket ratio stocks (value). Hong, Lim, and Stein (2000) find that analyst coverage is related to both momentum and institutional ownership. Nagel (2005) and Ali and Trombley (2006) use institutional ownership as a proxy for short sales constraints and find that stocks with greater short sales constraints (low institutional ownership) display greater momentum. To rule out these alternative explanations for our results, we compute residual institutional ownership in each stock by regressing current institutional ownership on the size of the stock, past six-month returns, the book-to-market ratio, and analyst following. ${ }^{9}$ Similar to raw institutional ownership, the greater the residual institutional ownership, the lower the individual investors' presence, and vice versa. We call this measure the residual individual investors' presence. We reproduce our portfolio and Fama-MacBeth (1973) regression results by replacing individual investors' presence based on raw institutional ownership with residual individual investors' presence based on residual institutional ownership.

\section{Results}

\section{A. Descriptive Statistics}

Although not reported in tables, our sample of stocks earned positive returns, on average, of around $1.1 \%$ per month over our sample period. The average capital gains overhang was negative at 17.03 with a standard deviation of $95.05 \%$ suggesting that there were many stocks

\footnotetext{
${ }^{9}$ Firms' market capitalization is used as proxy for size. Past six-month return is computed by compounding the past six months of the stock's monthly return. To compute the book-to-market ratio, we divide the firm's book value of the equity extracted from Compustat annual files by the market capitalization of the firm at the end of every month. We assume that it takes at least three months for the market to become aware of a firm's last financial year results. We use the number of estimates in the Institutional Brokers' Estimates System (IBES) summary files as the proxy for analysts following the firms.
} 
for which investors were sitting on unrealized losses. Our first (second) measure of individual investors' presence in stocks using raw institutional ownership (share turnover attributable to individual investors) averaged 55.17\% (28.71\%) although there is significant cross-sectional variability across stocks reflected in the standard deviation at $21.18 \%(20.59 \%)$. The time-series mean (median) of monthly cross-sectional correlation between our two measures of individual investors' presence in stocks is positive 54.85\% (56.65\%). This suggests that although share turnover attributable to individual investors and their ownership in stocks are related to each other, each measure captures a different aspect of individual investors' interest or influence on a stock.

Table I reports the results for the profitability of three momentum strategies evaluated in our study. We observe that in each of the three momentum strategies, winning (highest past return) portfolios outperform losing (lowest past return) portfolios over the holding period. The difference in the average monthly return between winning and losing portfolios is positive and statistically significant. For example, winning stocks outperform losing stocks by a statistically significant $0.209 \%$ per month for the $1 \times 3$ strategy, $0.481 \%$ per month for the $3 \times 3$ strategy, and $0.829 \%$ per month for the $6 \times 6$ strategy.

Also reported in Table I are the results of the regression specification we use to derive residual institutional ownership in the stocks. ${ }^{10}$ All the coefficients are statistically significant, suggesting that the chosen variables are important determinants of institutional ownership. Furthermore, our results are consistent with most past findings and indicate that institutional investors prefer stocks that are larger in size, have better past returns, have higher book-to-market ratios, and tend to be followed by larger number of analysts.

\section{B. Calendar-Time Portfolios Results}

Table II presents the results of portfolios sorted on past returns, capital gains overhang, and our first measure of individual investors' presence in stocks derived from institutional holdings in stocks. We first sort the stocks into three groups based on their past return. Each of the three return-based sorted portfolios is then further sorted into three portfolios based on capital gains overhang to obtain $3 \times 3$ portfolios. As mentioned earlier, if the disposition effect is an important determinant of momentum, then one would expect that within each return group, the high minus low capital gains overhang portfolios will have positive returns. Since our main hypothesis poses that individual investors drive the disposition effect, we would expect the returns of high minus low capital gains overhang portfolios to be higher, the greater the level of individual investors' presence. To test this, we further sort each of the $3 \times 3$ portfolios into three groups based on the level of individual investors' presence. We tried both independent sorting as well as dependent sorting for individual investors' presence and found similar results. In Table II, we report the results based on an independent sort on individual investors' presence.

Table II displays three panels as we test our main hypothesis on the $1 \times 3$ (Panel A), $3 \times 3$ (Panel B), and $6 \times 6$ (Panel C) momentum strategies. The table reports the average monthly returns to the high minus low capital gains overhang portfolios. Within each return group, we note that the returns to the high minus low capital gains overhang portfolios are positive irrespective of the level of individual investors' presence. The difference is statistically significant in all cases but one suggesting that capital gains overhang is an important determinant of momentum. This finding is consistent with Grinblatt and Han (2005) that controlling for past returns, capital

\footnotetext{
${ }^{10}$ These are based on pooled regressions although our results remain qualitatively similar if we employ Fama-MacBeth (1973) monthly regressions and use the time-series average of the coefficients.
} 


\section{Table I. Momentum and Residual Institutional Ownership}

Panels A, B, and $\mathrm{C}$ present summary statistics of three $(M \times N)$ momentum strategies. $(M \times N)$ strategy is the momentum portfolio with $M$-month ranking period and $N$-month holding period skipping a month after the ranking period, where $M$ is 1,3 , and 6 and $N$ is 3, 3, and 6 . Panel $\mathrm{D}$ is the result of pooled regressions of institutional ownership on various variables using individual firms. Institutional ownership is defined as the percentage of shares outstanding owned by all institutional investors in aggregate at the end of every quarter. Book-to-Market is BE/ME, where BE is the lagged Compustat book value of stockholders' equity (Item 216). We ignore any negative or zero book value. ME is market capitalization at the end of every month computed as the number of shares $\times$ price from CRSP files. Size is the market capitalization at the end of every month computed from CRSP files. To be included in the sample, a stock should have a price greater than or equal to $\$ 5$ and have a market capitalization greater than the smallest decile of NYSE stocks. The sample consists of all common stocks of the NYSE/AMEX/NASDAQ from CRSP that intersect with ISSM and TAQ files from the end of 1986 to December 2005. The $p$-values are reported in parentheses.

Panel A. $1 \times 3$ Strategy

Low return

$1.146(<.0004)$

Medium return

$1.354(<.0000)$

High return

$1.355(<.0000)$

High-low

$0.209(0.0230)$

Panel B. $3 \times 3$ Strategy

\begin{tabular}{ll}
\hline \hline Low return & $0.987(<.0000)$ \\
Medium return & $1.405(<.0000)$ \\
High return & $1.468(<.0000)$ \\
High-low & $0.481(<.0000)$
\end{tabular}

Panel C. $6 \times 6$ Strategy

Low return

Medium return

High return

$0.665(<.0117)$

High-low

1 18.0000$)$

$1.493(<.0000)$

$0.829(<.0000)$

\begin{tabular}{lcccccc}
\hline \hline \multicolumn{5}{c}{ Panel D. Regression Results for Residual Institutional Ownership } \\
\multicolumn{5}{c}{$I O_{i t}=\alpha_{1}+\beta_{1}(\text { Size })_{i t}+\beta_{2}(\text { Past_Six_Months_Return })_{i t}+\beta_{3}(\text { Book_Market })_{i t}+\beta_{4}($ Num_Anal $)+\varepsilon_{i t}$} \\
\hline \hline Intercept & Size & Past 6-Month Return & Book-to-Market & Num_Anal & Adj $\boldsymbol{R}^{\mathbf{2}}$ & Obs \\
\hline 29.9432 & 0.0004 & $\begin{array}{c}2.9689 \\
(<.0001)\end{array}$ & $\begin{array}{c}0.0257 \\
(<.0001)\end{array}$ & $(<.0001)$ & & \\
\hline \hline
\end{tabular}

gains overhang is strong predictor of future returns. More importantly, if we examine the returns across individual investors' presence groups, we see that the returns are more positive for high individual investors' presence group stocks as compared to low individual investors' presence group stocks. The last column in Table II presents the magnitude of this difference and its statistical significance. We observe that the differences are positive in all cases and statistically significant in all cases but one with the exception belonging to the medium return group in the $3 \times 3$ momentum strategy. For instance, for the $1 \times 3$ momentum strategy, we determine that the disposition effect-induced momentum is higher among high individual investors' presence stocks by around $0.45 \%[(0.721+0.238+0.392) / 3]$ per month when compared to low individual investors' presence stocks. 


\section{Table II. Average Monthly Returns of High-Low Capital Gains Overhang Portfolios within Each Momentum Portfolio across Individual Investors' Presence Group Based on Institutional Holding}

This table reports the average monthly returns of high minus low capital gains overhang portfolios within each momentum portfolio depending on individual investors' presence in each stock. Individual investor presence in each stock is derived as the percentage of shares outstanding not held by institutions. After we form three momentum portfolios (low return, medium return, and high return) on past returns, we form three capital gains overhang portfolios within each momentum portfolio. Then, we further create three portfolios based on individual investors' presence in each stock independently of the momentum and capital gains overhang portfolios. Panels A, B, and $\mathrm{C}$ are the results of $M \times N$ momentum portfolio with the $M$-month ranking period and the $N$-month holding period skipping a month after the ranking period, where $M$ is 1,3 , and 6 and $N$ is 3, 3, and 6. Capital gains overhang is computed as $\left(P_{t}-R P_{t}\right) / P_{t}$ at the end of each month, where $P_{t}$ is the price of stock at the end of month $t$, and $R P_{t}=\frac{1}{k} \sum_{n=1}^{T}\left(V_{t-n} \prod_{\tau=1}^{n-1}\left[1-V_{t-n+\tau}\right]\right) P_{t-n}$ where $V_{t}$ is the turnover of stock attributed to individual investors at $t . K$ is a constant that causes the weights on past prices to sum to one. Individual investors' trading volume is the aggregate shares volume associated with all trades of $\$ 10,000$ or less. Institutional ownership is the sum of the shares held by all institutions at the end of every quarter divided by the total outstanding shares in Thomson Financial 13-F filing data. To be included in the sample, the stock should have a price greater than or equal to $\$ 5$ and have a market capitalization greater than the smallest decile of NYSE stocks. The sample consists of all common stocks of the NYSE/AMEX/NASDAQ from CRSP that intersect with ISSM and TAQ files from the end of 1986 to December 2005. The $p$-values are reported in parentheses.

\begin{tabular}{lcccc}
\hline \hline $\begin{array}{l}\text { Past Return } \\
\text { Group }\end{array}$ & \multicolumn{3}{c}{ Individual Investors' Presence Group } \\
\cline { 2 - 4 } & $\begin{array}{c}\text { High Individual } \\
\text { Investor } \\
\text { Presence Group }\end{array}$ & $\begin{array}{c}\text { Medium } \\
\text { Individual } \\
\text { Investor } \\
\text { Presence Group }\end{array}$ & $\begin{array}{c}\text { Low Individual } \\
\text { Investor } \\
\text { Presence Group }\end{array}$ & $\begin{array}{c}\text { High-Low } \\
\text { Individual } \\
\text { Investor } \\
\text { Presence Group }\end{array}$ \\
\hline \hline
\end{tabular}

Panel A. $1 \times 3$ Strategy

\begin{tabular}{lcccc}
\hline \hline Low return (R1) & 1.174 & 0.766 & 0.454 & 0.721 \\
& $(<.0001)$ & $(0.0030)$ & $(0.0041)$ & $(0.0161)$ \\
Medium return (R2) & 0.525 & 0.559 & 0.288 & 0.238 \\
& $(0.0083)$ & $(0.0035)$ & $(0.0272)$ & $(0.0330)$ \\
High return (R3) & 1.172 & 0.989 & 0.780 & 0.392 \\
& $(<.0001)$ & $(0.0006)$ & $(0.0033)$ & $(0.0428)$ \\
\hline
\end{tabular}

Panel B. $3 \times 3$ Strategy

\begin{tabular}{lcccc}
\hline \hline Low return (R1) & 0.905 & 0.937 & 0.457 & 0.447 \\
& $(0.0017)$ & $(0.0004)$ & $(0.0174)$ & $(0.0342)$ \\
Medium return (R2) & 0.412 & 0.551 & 0.306 & 0.107 \\
& $(0.0479)$ & $(0.0018)$ & $(0.0206)$ & $(0.1574)$ \\
High return (R3) & 1.159 & 1.091 & 0.689 & 0.470 \\
& $(<.0001)$ & $(<.0001)$ & $(0.0085)$ & $(0.0310)$ \\
\hline \hline
\end{tabular}

Panel C. $6 \times 6$ Strategy

\begin{tabular}{lcccc}
\hline \hline Low return (R1) & 0.719 & 0.611 & 0.144 & 0.575 \\
& $(0.0197)$ & $(0.0258)$ & $(0.0305)$ & $(0.0298)$ \\
Medium return (R2) & 0.364 & 0.401 & 0.109 & 0.255 \\
& $(0.0254)$ & $(0.0207)$ & $(0.1623)$ & $(0.0434)$ \\
High return (R3) & 0.476 & 0.498 & 0.355 & 0.121 \\
& $(0.0374)$ & $(0.0316)$ & $(0.0437)$ & $(0.0967)$ \\
\hline \hline
\end{tabular}


Overall, our results are supportive of our main hypothesis that disposition effect-induced momentum in stocks is increasing in individual investors' presence in stocks. The only case of statistically insignificance occurs in the medium return group for the $3 \times 3$ momentum strategy. This may be because the stocks in the medium return group are less likely to have strong disposition effects as these stocks are less likely to have significant price-sensitive information released during the ranking period for individual investors to underreact due to their disposition behavior. Therefore, it is less likely that we will find evidence in support of our hypothesis in the medium return group.

To control for stock characteristics related to institutional ownership as a potential explanations of our results, we repeat our analysis using residual individual investors' presence computed from residual institutional ownership. The residual institutional ownership is obtained by regressing raw institutional ownership on firm characteristics such as size, book-to-market, past return, and analyst following as in the regression model shown in Table I. High (low) levels of residual institutional ownership correspond to low (high) levels of residual individual investors' presence. Table III presents our results using residual individual investors' presence. Similar to the results in Table II, we see that the high minus low capital gains overhang portfolios earn statistically significant positive returns across all residual individual investors' presence groups. The returns are more positive for high residual individual investors' presence stocks as compared to the low individual investors' presence groups stocks shown in the last column. The average returns in the last column continue to be positive in all cases although they are not statistically significant in three instances compared to one in Table II. However, the three insignificant cases happen to be for the medium return groups where it is less likely that the disposition effect will explain future return.

Additionally, the magnitude of the difference in the last column in Tables II and III is generally higher for the low-return groups when compared to the high-return groups. It could be argued that presence of short sales constraints is driving this result. The reasoning is as follows. Due to short sales constraints, investors are not able to fully incorporate adverse information into the stock prices in the ranking period for the low-return group of stocks. This causes underreaction to the adverse information leading to momentum in the low-return group. As institutional ownership is negatively related to short sales constraints and since our first measure of individual investors' presence in stocks is based on institutional ownership, our returns to high minus low individual investors' presence in stocks in the low-return group may be a reflection of short sales constraints. However, we note that in Tables II and III, individual investors' induced disposition effect explains future returns in the high-return group as well. Additionally, in Table III, our measure of residual institutional ownership controls for size and book-to-market ratio, and, to some extent, also controls for short sale constraints (D'Avolio, 2002).

Although we have eliminated alternative explanations of the relationship between institutional ownership and momentum in the above analysis, our results will be more powerful if we can find another measure of investor population in each stock that is subject to the disposition effect that is unrelated to institutional ownership. This is especially important since several studies use institutional holding as a proxy for short sale constraints. Since our analysis is based on residual institutional holdings, it alleviates this concern to some degree. To this end, we use the average fraction of share turnover in each stock in a month that could be attributed to individual investors. We assume that all trades equal to or less than $\$ 10,000$ proxy for the trades of individual investors. The greater the fraction of such trading volume relative to total trading volume, the greater the proportion of investors subject to disposition effect in the stock. This new measure is correlated with raw individual ownership at $54.85 \%$, suggesting that it does capture a somewhat different aspect of an individual investor's presence in a stock. 


\section{Table III. Average Monthly Returns of High-Low Capital Gains Overhang Portfolios within Each Momentum Portfolio across Individual Investors' Presence Group Based on Residual Institutional Holding}

This table presents the average monthly returns of high minus low capital gains overhang portfolios within each momentum portfolio depending on individual investors' presence in each stock. Individual investor presence in each stock is derived from the residual institutional holdings. After we form three momentum portfolios (low return, medium return, and high return) on past returns, we create three capital gains overhang portfolios within each momentum portfolio. Then, we further form three portfolios based on individual investors' presence in each stock independently of the momentum and capital gains overhang portfolios. Panels A, B, and $\mathrm{C}$ are the results of the $M \times N$ momentum portfolio with the $M$-month ranking period and the $N$-month holding period skipping a month after the ranking period, where $M$ is 1,3 , and 6 and $N$ is 3, 3, and 6. Capital gains overhang is computed as $\left(P_{t}-R P_{t}\right) / P_{t}$ at the end of each month, where $P_{t}$ is the price of stock at the end of month $t$, and $R P_{t}=\frac{1}{k} \sum_{n=1}^{T}\left(V_{t-n} \prod_{\tau=1}^{n-1}\left[1-V_{t-n+\tau}\right]\right) P_{t-n}$ where $V_{t}$ is turnover of stock attributed to individual investors at $t . K$ is a constant that causes the weights on past prices to sum to one. Individual investors' trading volume is the aggregate shares volume associated with all trades of $\$ 10,000$ or less. Residual institutional ownership for each stock is the residuals from the regression of current institutional ownership on size of the stock, past six months returns, book-to-market ratio, and analyst following. To be included in the sample, a stock should have price greater than or equal to $\$ 5$ and have a market capitalization greater than the smallest decile of NYSE stocks. The sample consists of all common stocks of the NYSE/AMEX/NASDAQ from CRSP that intersect with ISSM and TAQ files from the end of 1986 to December 2005. The $p$-values are reported in parentheses.

\begin{tabular}{llccc}
\hline \hline $\begin{array}{l}\text { Past Return } \\
\text { Group }\end{array}$ & \multicolumn{3}{c}{ Individual Investors' Presence Group } \\
\cline { 2 - 4 } & $\begin{array}{c}\text { High Individual } \\
\text { Investor } \\
\text { Presence Group }\end{array}$ & $\begin{array}{c}\text { Medium } \\
\text { Individual } \\
\text { Investor } \\
\text { Presence Group }\end{array}$ & $\begin{array}{c}\text { Low Individual } \\
\text { Investor } \\
\text { Presence Group }\end{array}$ & $\begin{array}{c}\text { High-Low } \\
\text { Individual } \\
\text { Investor } \\
\text { Presence Group }\end{array}$ \\
\hline \hline
\end{tabular}

Panel A. $1 \times 3$ Strategy

\begin{tabular}{lcccc}
\hline \hline Low return (R1) & 1.030 & 0.847 & 0.414 & 0.616 \\
& $(0.0012)$ & $(0.0018)$ & $(0.0049)$ & $(0.0235)$ \\
Medium return (R2) & 0.409 & 0.585 & 0.408 & 0.001 \\
& $(0.0052)$ & $(0.0034)$ & $(0.0043)$ & $(0.9962)$ \\
High return (R3) & 1.052 & 0.972 & 0.868 & 0.184 \\
& $(0.0002)$ & $(0.0007)$ & $(0.0013)$ & $(0.0487)$ \\
\hline
\end{tabular}

Panel B. $3 \times 3$ Strategy

\begin{tabular}{lcccc}
\hline \hline Low return (R1) & 0.981 & 0.957 & 0.467 & 0.514 \\
& $(0.0027)$ & $(0.0002)$ & $(0.0402)$ & $(0.0472)$ \\
Medium return (R2) & 0.361 & 0.438 & 0.281 & 0.080 \\
& $(0.0437)$ & $(0.0252)$ & $(0.0098)$ & $(0.6880)$ \\
High return (R3) & 1.324 & 0.975 & 0.779 & 0.544 \\
& $(<.0001)$ & $(0.0002)$ & $(0.0027)$ & $(0.0307)$ \\
\hline \hline
\end{tabular}

Panel C. $6 \times 6$ Strategy

\begin{tabular}{lcccc}
\hline \hline Low return (R1) & 0.488 & 0.391 & 0.137 & 0.351 \\
& $(0.0184)$ & $(0.0257)$ & $(0.0672)$ & $(0.0342)$ \\
Medium return (R2) & 0.201 & 0.248 & 0.178 & 0.023 \\
& $(0.0639)$ & $(0.0538)$ & $(0.0708)$ & $(0.5689)$ \\
High return (R3) & 0.531 & 0.469 & 0.325 & 0.206 \\
& $(0.0040)$ & $(0.0058)$ & $(0.0076)$ & $(0.0811)$ \\
\hline \hline
\end{tabular}


We reproduce Table II by sorting $3 \times 3$ portfolios on past return and capital gains overhang into three groups based on our new measure. We classify these groups as disposition-motivated trading groups. The results are presented in Table IV.

Similar to Tables II and III, we observe that most of the high minus low capital gains overhang portfolios earn statistically significant positive returns across the disposition-motivated trading groups. In only 3 out of 27 portfolios, returns between high minus low capital gains overhang portfolios are statistically insignificant though positive. Interestingly, two of these occur in the low-disposition-motivated trading group, which is consistent with our hypothesis. The average returns in the last column continue to be positive in all cases though they are not statistically significant for the $6 \times 6$ strategy. Furthermore, the magnitude of difference is larger for the high-return group when compared to the low-return group for the $1 \times 3$ and $3 \times 3$, while for the $6 \times 6$ strategy; the magnitude of difference is similar. This suggests that short sale constraints are not driving the result given the strong evidence we find for our hypothesis within the highreturn groups. We address this issue further in the next section using Fama-MacBeth regressions. Overall, our results using this new measure of individual investors' presence in stocks are in conformance with the idea that disposition effect-induced momentum in stocks is increasing in investor population in each stock that is subject to the disposition effect.

\section{Fama-MacBeth: Regressions Results}

One could argue that we could increase the power of our tests by sorting the stocks into finer groups. However, this is not practical when we are doing three-way sorts. Therefore, similar to Grinblatt and Han (2005), we test our hypothesis using monthly cross-sectional Fama-MacBeth (1973) regressions as previously mentioned. Table V presents the average estimated coefficients along with the $p$-values based on the time series of monthly cross-sectional regression coefficients. We notice that past return and capital gains overhang are positively correlated with future returns in univariate regressions. When we include both in the same regression, we notice that the coefficient on past returns is no longer statistically significant for the $1 \times 3$ and $3 \times 3$ momentum strategies (Model 3). The coefficient on past return remains positive and statistically significant for the $6 \times 6$ strategy. This result suggests that the past return's predictive power for future returns is not entirely subsumed by the capital gains overhang variable for the $6 \times 6$ strategy.

Our primary variable of interest is the interaction variable between our measures of individual investors' presence in stocks and capital gains overhang. The three different measures are based on raw institutional holding, residual institutional holding, and fraction of trading volume attributed to individual investors. We note that the coefficient on this interaction variable is positive and statistically significant for the $1 \times 3,3 \times 3$, and $6 \times 6$ momentum strategies for all three measures of individual investors' presence in stocks. For example, in $1 \times 3$ trading strategy for Model 6 , the coefficient of the interaction term is 0.0042 and is statistically significant at $1 \%$. We see similar results for other strategies in Models 4 and 5 as well. Therefore, the evidence suggests that disposition effect-induced momentum is higher among stocks with greater individual investors' presence. We also ran separate monthly regressions based on Model 3, 4, 5, and 6 for each of the three (high, medium, low) measures of investor population in each stock that is subject to the disposition effect. In unreported results, we find that the coefficient on capital gains overhang variable is larger for high individual ownership/high fraction of trading by individuals stocks suggesting that the power of capital gains overhang to explain future returns increases as investor population in each stock that is subject to the disposition effect increases. We found similar results when we split our measures of investor population in each stock that is subject to the disposition effect into five groups rather than three. In order to reaffirm that short sale constraints are not 


\section{Table IV. Average Monthly Returns of High-Low Capital Gains Overhang Portfolios within Each Momentum Portfolio across Individual Investors' Presence Group Based on Disposition-Motivated Trades}

This table reports the average monthly returns of high minus low capital gains overhang portfolios within each momentum portfolio depending on individual investors' presence in each stock. Individual investor presence in each stock is derived as the monthly average of the daily fraction of the individual investors' trading volume. After we form three momentum portfolios (low return, medium return, and high return) on past returns, we create three capital gains overhang portfolios within each momentum portfolio. Then, we further form three portfolios based on individual investors' presence in each stock, independently of the momentum and capital gains overhang portfolios. Panels A, B, and $\mathrm{C}$ are the results of the $M \times N$ momentum portfolio with the $M$-month ranking period and the $N$-month holding period skipping a month after the ranking period, where $M$ is 1,3 , and 6 and $N$ is 3,3, and 6. Capital gains overhang is computed as $\left(P_{t}-R P_{t}\right) / P_{t}$ at the end of each month, where $P_{t}$ is the price of stock at the end of month $t$, and $R P_{t}=\frac{1}{k} \sum_{n=1}^{T}\left(V_{t-n} \prod_{\tau=1}^{n-1}\left[1-V_{t-n+\tau}\right]\right) P_{t-n}$ where $V_{t}$ is turnover of stock attributed to individual investors at $t . K$ is a constant that causes the weights on past prices to sum to one. Individual investors' trading volume is the aggregate shares volume associated with all trades of $\$ 10,000$ or less. To be included in the sample, a stock should have price greater than or equal to $\$ 5$ and have a market capitalization greater than the smallest decile of NYSE stocks. The sample consists of all common stocks of the NYSE/AMEX/NASDAQ from CRSP that intersect with ISSM and TAQ files from the end of 1986 to December 2005. The $p$-values are reported in parentheses.

\begin{tabular}{lcccc}
\hline \hline $\begin{array}{l}\text { Past Return } \\
\text { Group }\end{array}$ & \multicolumn{3}{c}{ Individual Investors' Presence Group } \\
\cline { 2 - 5 } & $\begin{array}{c}\text { High Individual } \\
\text { Investor } \\
\text { Presence Group }\end{array}$ & $\begin{array}{c}\text { Medium } \\
\text { Individual } \\
\text { Investor } \\
\text { Presence Group }\end{array}$ & $\begin{array}{c}\text { Low Individual } \\
\text { Investor } \\
\text { Presence Group }\end{array}$ & $\begin{array}{c}\text { High-Low } \\
\text { Individual } \\
\text { Investor } \\
\text { Presence Group }\end{array}$ \\
\hline \hline
\end{tabular}

Panel A. $1 \times 3$ Strategy

\begin{tabular}{lcccc}
\hline \hline Low return (R1) & 0.966 & 0.781 & 0.675 & 0.292 \\
& $(0.0002)$ & $(0.0069)$ & $(0.0145)$ & $(0.0286)$ \\
Medium return (R2) & 0.859 & 0.443 & 0.152 & 0.707 \\
& $(<.0001)$ & $(0.0234)$ & $(0.0430)$ & $(0.0005)$ \\
High return (R3) & 1.246 & 1.082 & 0.783 & 0.463 \\
& $(<.0001)$ & $(<.0001)$ & $(0.0051)$ & $(0.0402)$ \\
\hline \hline
\end{tabular}

Panel B. $3 \times 3$ Strategy

\begin{tabular}{lcccc}
\hline \hline Low return (R1) & 0.870 & 0.875 & 0.770 & 0.099 \\
& $(0.0007)$ & $(0.0027)$ & $(0.0037)$ & $(0.0356)$ \\
Medium return (R2) & 0.707 & 0.501 & 0.402 & 0.305 \\
& $(0.0001)$ & $(0.0047)$ & $(0.0313)$ & $(0.0640)$ \\
High return (R3) & 1.234 & 1.183 & 0.609 & 0.6247 \\
& $(<.0001)$ & $(<.0001)$ & $(0.0228)$ & $(0.0322)$ \\
\hline
\end{tabular}

Panel C. $6 \times 6$ Strategy

\begin{tabular}{lcccc}
\hline \hline Low return (R1) & 0.602 & 0.446 & 0.247 & 0.353 \\
& $(0.0187)$ & $(0.1426)$ & $(0.2040)$ & $(0.1322)$ \\
Medium return (R2) & 0.180 & 0.347 & 0.153 & 0.027 \\
& $(0.0363)$ & $(0.0396)$ & $(0.1778)$ & $(0.1896)$ \\
High return (R3) & 0.768 & 0.506 & 0.378 & 0.391 \\
& $(0.0018)$ & $(0.0241)$ & $(0.0810)$ & $(0.1224)$ \\
\hline \hline
\end{tabular}




\section{Table V. Fama-MacBeth Cross-Sectional Regression: Three Exchanges}

This table reports the results of the Fama-MacBeth (1973) monthly cross-sectional regressions of returns on past return, capital gains overhang, and measures of individual investors' presence $\times$ capital gains overhang. Individual investors' presence in each stock is based on institutional holding, residual institutional holding, and fraction of shares traded by individual investors. The $p$-values in parentheses are based on corrected $t$-statistics using Newey and West (1987) with an adjustment for autocorrelation. Panels A, B, and C are the results of the $M \times N$ momentum portfolio with the $M$-month ranking period and the $N$-month holding period skipping a month after the ranking period, where $M$ is 1,3 , and 6 and $N$ is 3,3 , and 6. Capital gains overhang is computed as $\left(P_{t}-R P_{t}\right) / P_{t}$ at the end of each month, where $P_{t}$ is the price of stock at the end of month $t$, and $R P_{t}=\frac{1}{k} \sum_{n=1}^{T}\left(V_{t-n} \prod_{\tau=1}^{n-1}\left[1-V_{t-n+\tau}\right]\right) P_{t-n}$ where $V_{t}$ is turnover of stock attributed to individual investors at $t . K$ is a constant that causes the weights on past prices to sum to one. Individual investors' trading volume is the aggregate shares volume associated with all trades of $\$ 10,000$ or less. Institutional ownership is the sum of the shares held by all institutions at the end of every quarter divided by the total outstanding shares in Thomson Financial 13-F filing data. Residual institutional ownership for each stock is the residuals from the regression of current institutional ownership on size of the stock, past six months returns, book-to-market ratio, and number of analysts. We assign 1, 0 , and -1 for high, medium, and low individual investors' presence. To be included in the sample, a stock should have price greater than or equal to $\$ 5$ and have a market capitalization greater than the smallest decile of NYSE stocks. The sample consists of all common stocks of the NYSE/AMEX/NASDAQ from CRSP that intersect with ISSM and TAQ files from the end of 1986 to December 2005. Interaction1 in Model 4 is an interaction term between the measure of individual investors' presence based on institutional holdings and capital gains overhang. Interaction 2 in Model 5 is an interaction term between the measure of individual investors' presence based on residual institutional holding and capital gains overhang. Interaction1 in Model 6 is an interaction term between the measure of individual investors' presence based on individual investors' fraction of trading volume and capital gains overhang.

\begin{tabular}{|c|c|c|c|c|c|c|}
\hline & Model 1 & Model 2 & Model 3 & Model 4 & Model 5 & Model 6 \\
\hline \multicolumn{7}{|c|}{ Panel A. $1 \times 3$ Strategy } \\
\hline Past return & $\begin{array}{c}0.0057 \\
(0.0482)\end{array}$ & & $\begin{array}{c}-0.0047 \\
(0.1369)\end{array}$ & $\begin{array}{c}-0.0045 \\
(0.1265)\end{array}$ & $\begin{array}{c}-0.0053 \\
(0.1097)\end{array}$ & $\begin{array}{c}-0.0045 \\
(0.1245)\end{array}$ \\
\hline Capital gains overhang & & $\begin{array}{c}0.0159 \\
(<.0001)\end{array}$ & $\begin{array}{c}0.0173 \\
(<.0001)\end{array}$ & $\begin{array}{c}0.0172 \\
(<.0001)\end{array}$ & $\begin{array}{c}0.0164 \\
(<.0001)\end{array}$ & $\begin{array}{c}0.0165 \\
(<.0001)\end{array}$ \\
\hline Interaction 1 & & & & $\begin{array}{c}0.0039 \\
(0.0001)\end{array}$ & & $\begin{array}{c}0.0042 \\
(0.0001)\end{array}$ \\
\hline Interaction2 & & & & & $\begin{array}{c}0.0031 \\
(0.0009)\end{array}$ & \\
\hline \multicolumn{7}{|c|}{ Panel B. $3 \times 3$ Strategy } \\
\hline Past return & $\begin{array}{c}0.0085 \\
(<.0001)\end{array}$ & & $\begin{array}{c}-0.0019 \\
(0.5186)\end{array}$ & $\begin{array}{c}-0.0019 \\
(0.3986)\end{array}$ & $\begin{array}{c}-0.0039 \\
(0.1191)\end{array}$ & $\begin{array}{r}-0.0017 \\
(0.4264)\end{array}$ \\
\hline Capital gains overhang & & $\begin{array}{c}0.0160 \\
(<.0001)\end{array}$ & $\begin{array}{c}0.0175 \\
(<.0001)\end{array}$ & $\begin{array}{c}0.0174 \\
(<.0001)\end{array}$ & $\begin{array}{c}0.0173 \\
(<.0001)\end{array}$ & $\begin{array}{c}0.0167 \\
(<.0001)\end{array}$ \\
\hline Interaction 1 & & & & $\begin{array}{c}0.0042 \\
(<.0001)\end{array}$ & & $\begin{array}{c}0.0043 \\
(<.0001)\end{array}$ \\
\hline Interaction 2 & & & & & $\begin{array}{c}0.0035 \\
(0.0002)\end{array}$ & \\
\hline \multicolumn{7}{|c|}{ Panel C. $6 \times 6$ Strategy } \\
\hline Past return & $\begin{array}{c}0.0099 \\
(<.0001)\end{array}$ & & $\begin{array}{c}0.0048 \\
(0.0033)\end{array}$ & $\begin{array}{c}0.0049 \\
(<.0001)\end{array}$ & $\begin{array}{c}0.0048 \\
(0.0001)\end{array}$ & $\begin{array}{c}0.0049 \\
(<.0001)\end{array}$ \\
\hline Capital gains overhang & & $\begin{array}{c}0.0142 \\
(<.0001)\end{array}$ & $\begin{array}{c}0.0114 \\
(<.0001)\end{array}$ & $\begin{array}{c}0.0113 \\
(<.0001)\end{array}$ & $\begin{array}{c}0.0103 \\
(<.0001)\end{array}$ & $\begin{array}{c}0.0107 \\
(<.0001)\end{array}$ \\
\hline Interaction1 & & & & $\begin{array}{c}0.0031 \\
(<.0001)\end{array}$ & & $\begin{array}{c}0.0036 \\
(<.0001)\end{array}$ \\
\hline Interaction 2 & & & & & $\begin{array}{c}0.0024 \\
(0.0005)\end{array}$ & \\
\hline
\end{tabular}


driving our results, we rerun the monthly Fama-MacBeth (1973) regressions by excluding stocks in the bottom institutional ownership quintile as these represent those stocks that are most likely to suffer from short sale constraints. The results (not reported) are similar to those reported in Table V and suggest that our findings are robust to excluding stocks with short sale constraints.

It has long been known that reported trading volumes on NASDAQ are overstated due to double counting and interdealer dealings (Atkins and Dyl, 1997; Anderson and Dyl, 2005, 2007). Since we use share turnover in our measure of capital gains overhang without any adjustment, as a check of robustness we drop all NASDAQ stocks from our sample and reproduce Table V. ${ }^{11}$ The results using only the NYSE and AMEX are presented in Table VI. The coefficients of the interaction variable become somewhat smaller in magnitude than those shown in Table $\mathrm{V}$, but they remain statistically significant with a positive sign. Thus, our results are robust whether we include or exclude NASDAQ stocks in the sample.

\section{Uncertainty, Disposition Effect, and Momentum}

In a recent paper, Kumar (2009) finds that individual investors exhibit a stronger disposition effect when stocks are hard to value. Therefore, one could argue that if the disposition effect is an important determinant of momentum profits, we would expect disposition-induced momentum to be stronger for stocks that are hard to value. Moreover, if investors display a greater disposition effect when stocks are hard to value, then our measures of investors' presence in each stock that is subject to this effect should explain the greater amount of momentum in such stocks.

To test this hypothesis, in each portfolio formation month, we separate stocks into three groups based on firm-level uncertainty and rerun our monthly Fama-MacBeth (1973) regressions separately for each group of stock. Firm-level uncertainty is measured by monthly idiosyncratic volatility. As in Kumar (2009), the monthly idiosyncratic volatility is the variance of the residuals from a four-factor model using daily returns data excluding stocks with fewer than 17 daily observations. The difference in the estimated model coefficients between the highest and lowest level of uncertainty groups is reported in Table VII.

All the differences in coefficients are positive and statistically significant, suggesting that disposition effect-induced momentum is higher among hard-to-value stocks and that individual investors' presence drives disposition-induced momentum more so among these stocks. We also notice that controlling for past returns, capital gains overhang has greater predictive power for future returns in hard-to-value stocks.

\section{Conclusion}

In this study, we hypothesize that since individual investors are prone to the disposition effect, disposition effect-induced momentum should be stronger for stocks with greater individual investor presence. Consistent with our hypothesis, we find that the ability of the disposition effect to explain momentum increases with the level of individual investors' presence in the stock. This result is robust to alternative ways of defining individual investor's presence in a stock. Also, this result holds among both high-return and low-return groups, implying that short sale constraints are not driving our result. Furthermore, consistent with Kumar (2009) who finds that individual investors display greater disposition effects among hard-to-value stocks, we find that individual

\footnotetext{
${ }^{11}$ We also reproduced Tables II-IV after dropping NASDAQ stocks and found qualitatively similar results to what are reported in these tables.
} 


\section{Table VI. Fama-MacBeth Cross-Sectional Regression: NYSE + AMEX}

This table presents the results of the Fama-MacBeth (1973) monthly cross-sectional regressions of returns on past return, capital gains overhang, and measures of individual investors' presence $\times$ capital gains overhang. Individual investors' presence in each stock is based on institutional holding, residual institutional holding, and fraction of shares traded by individual investors. The $p$-values in parentheses are based on corrected $t$-statistics using Newey and West (1987) with an adjustment for autocorrelation. Panels A, B, and C are the results of the $M \times N$ momentum portfolio with the $M$-month ranking period and the $N$-month holding period skipping a month after the ranking period, where $M$ is 1,3 , and 6 and $N$ is 3, 3, and 6. Capital gains overhang is computed as $\left(P_{t}-R P_{t}\right) / P_{t}$ at the end of each month, where $P_{t}$ is the price of stock at the end of month $t$, and $R P_{t}=\frac{1}{k} \sum_{n=1}^{T}\left(V_{t-n} \prod_{\tau=1}^{n-1}\left[1-V_{t-n+\tau}\right]\right) P_{t-n}$ where $V_{t}$ is turnover of stock attributed to individual investors at $t . K$ is a constant that causes the weights on past prices to sum to one. Individual investors' trading volume is the aggregate shares volume associated with all trades of $\$ 10,000$ or less. Institutional ownership is the sum of the shares held by all institutions at the end of every quarter divided by the total outstanding shares in Thomson Financial 13-F filing data. Residual institutional ownership for each stock is the residuals from the regression of current institutional ownership on size of the stock, past six months returns, book-to-market ratio, and number of analysts. We assign 1, 0, and -1 for high, medium, and low individual investors' presence. To be included in the sample, stock should have price greater than or equal to $\$ 5$ and market capitalization greater than the smallest decile of NYSE stocks. The sample consists of all common stocks of the NYSE/AMEX from CRSP that intersect with ISSM and TAQ files from the end of 1986 to December 2005. Interaction1 in Model 4 is an interaction term between the measure of individual investors' presence based on institutional holding and capital gains overhang. Interaction2 in Model 5 is an interaction term between the measure of individual investors' presence based on residual institutional holding and capital gains overhang. Interaction 1 in Model 6 is an interaction term between the measure of individual investors' presence based on individual investors' fraction of trading volume and capital gains overhang. The $p$-values are reported in parentheses.

\begin{tabular}{|c|c|c|c|c|c|c|}
\hline & Model 1 & Model 2 & Model 3 & Model 4 & Model 5 & Model 6 \\
\hline \multicolumn{7}{|c|}{ Panel A. $1 \times 3$ Strategy } \\
\hline Past return & $\begin{array}{c}0.0048 \\
(0.0401)\end{array}$ & & $\begin{array}{r}-0.0078 \\
(0.0063)\end{array}$ & $\begin{array}{c}-0.0075 \\
(0.0068)\end{array}$ & $\begin{array}{c}-0.0086 \\
(0.0045)\end{array}$ & $\begin{array}{c}-0.0077 \\
(0.0049)\end{array}$ \\
\hline Capital gains overhang & & $\begin{array}{c}0.0131 \\
(<.0001)\end{array}$ & $\begin{array}{c}0.0151 \\
(<.0001)\end{array}$ & $\begin{array}{c}0.0149 \\
(<.0001)\end{array}$ & $\begin{array}{c}0.0145 \\
(<.0001)\end{array}$ & $\begin{array}{c}0.0143 \\
(<.0001)\end{array}$ \\
\hline Interaction 1 & & & & $\begin{array}{c}0.0021 \\
(0.0155)\end{array}$ & & $\begin{array}{c}0.0045 \\
(<.0001)\end{array}$ \\
\hline Interaction 2 & & & & & $\begin{array}{c}0.0007 \\
(0.0420)\end{array}$ & \\
\hline \multicolumn{7}{|c|}{ Panel B. $3 \times 3$ Strategy } \\
\hline Past return & $\begin{array}{c}0.0076 \\
(0.0037)\end{array}$ & & $\begin{array}{r}-0.0049 \\
(0.0850)\end{array}$ & $\begin{array}{c}-0.0048 \\
(0.0232)\end{array}$ & $\begin{array}{r}-0.0074 \\
(0.0016)\end{array}$ & $\begin{array}{r}-0.0048 \\
(0.0208)\end{array}$ \\
\hline Capital gains overhang & & $\begin{array}{c}0.0132 \\
(<.0001)\end{array}$ & $\begin{array}{c}0.0159 \\
(<.0001)\end{array}$ & $\begin{array}{c}0.0159 \\
(<.0001)\end{array}$ & $\begin{array}{c}0.0162 \\
(<.0001)\end{array}$ & $\begin{array}{c}0.0152 \\
(<.0001)\end{array}$ \\
\hline Interaction 1 & & & & $\begin{array}{c}0.0024 \\
(0.0052)\end{array}$ & & $\begin{array}{c}0.0045 \\
(<.0001)\end{array}$ \\
\hline Interaction 2 & & & & & $\begin{array}{c}0.0012 \\
(0.0243) \\
\end{array}$ & \\
\hline \multicolumn{7}{|c|}{ Panel C. $6 \times 6$ Strategy } \\
\hline Past return & $\begin{array}{c}0.0089 \\
(<.0001)\end{array}$ & & $\begin{array}{c}0.0043 \\
(0.0066)\end{array}$ & $\begin{array}{c}0.0044 \\
(<.0001)\end{array}$ & $\begin{array}{c}0.0043 \\
(0.0004)\end{array}$ & $\begin{array}{c}0.0045 \\
(<.0001)\end{array}$ \\
\hline Capital gains overhang & & $\begin{array}{c}0.0122 \\
(<.0001)\end{array}$ & $\begin{array}{c}0.0097 \\
(0.0002)\end{array}$ & $\begin{array}{c}0.0095 \\
(<.0001)\end{array}$ & $\begin{array}{c}0.0091 \\
(<.0001)\end{array}$ & $\begin{array}{c}0.0089 \\
(<.0001)\end{array}$ \\
\hline Interaction 1 & & & & $\begin{array}{c}0.0012 \\
(0.0301)\end{array}$ & & $\begin{array}{c}0.0037 \\
(<.0001)\end{array}$ \\
\hline Interaction 2 & & & & & $\begin{array}{c}0.0003 \\
(0.0681)\end{array}$ & \\
\hline
\end{tabular}




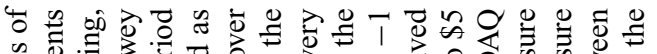



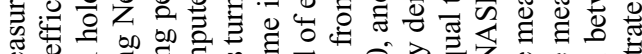

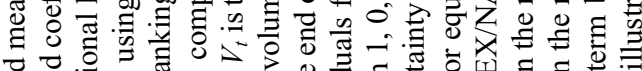

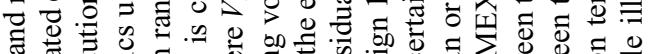



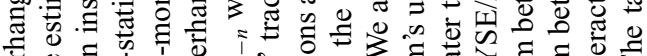



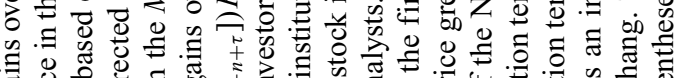



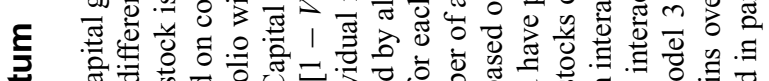

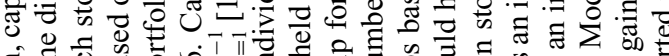

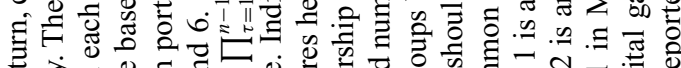



ज

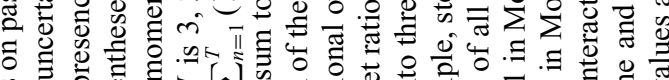



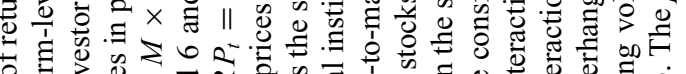
O

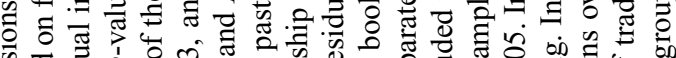

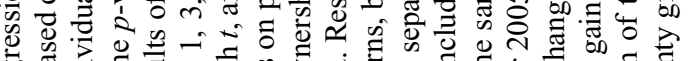

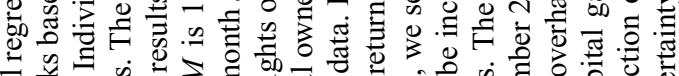

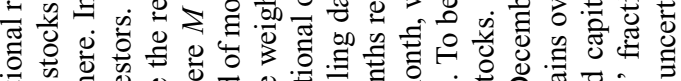



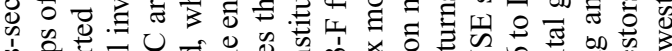

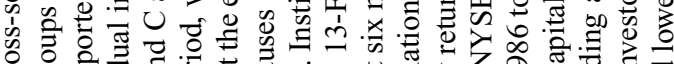
o

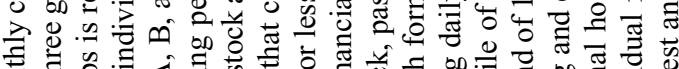

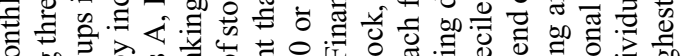



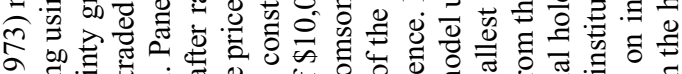

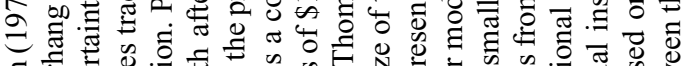

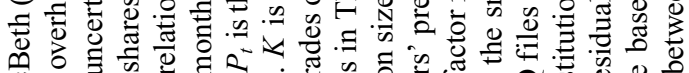

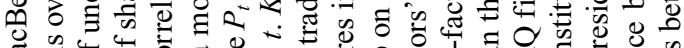

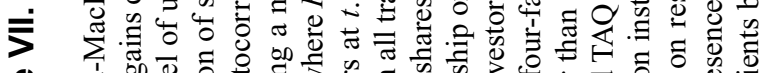
๙

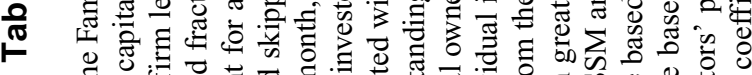

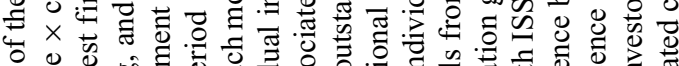

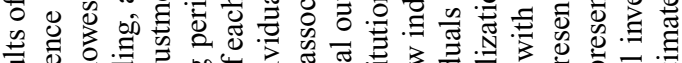

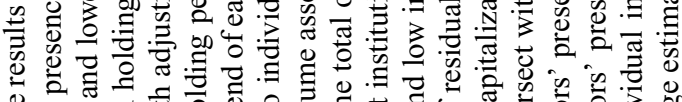
可





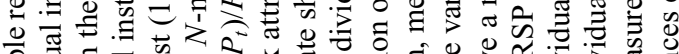

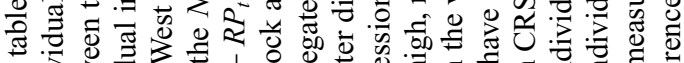



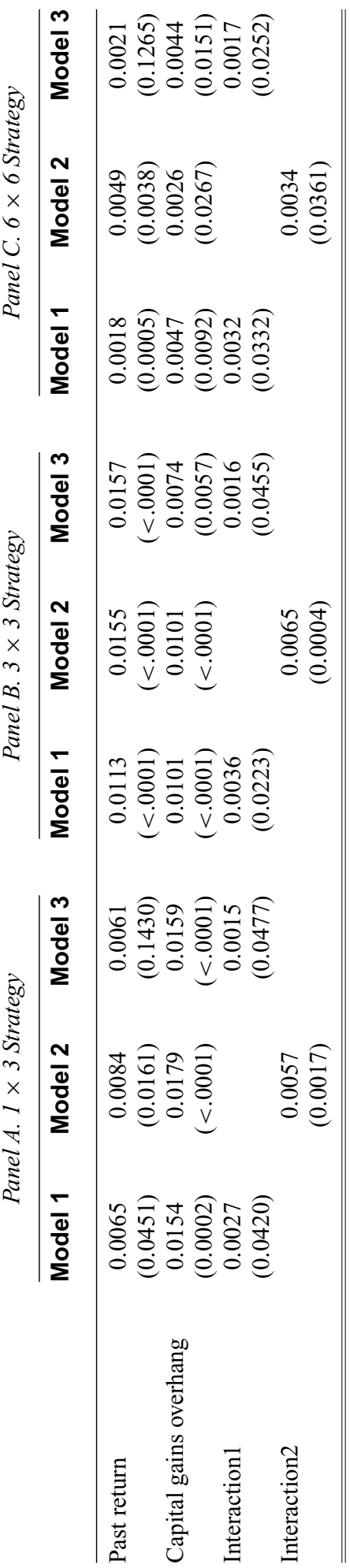


investors drive disposition effect-induced momentum among hard-to-value stocks. This study sheds further light on the momentum anomaly by demonstrating that individual investors influence the momentum effect based on their behavioral biases known as the disposition effect and that this influence is greater for hard-to-value stocks.

\section{References}

Agarwal, V. and R. Taffler, 2008, "Does Financial Distress Risk Drive the Momentum Anomaly," Financial Management 37, 461-464.

Ali, A. and M. Trombley, 2006, "Short Sales Constraints and Momentum in Stock Returns," Journal of Business Finance and Accounting 33, 587-615.

Anderson, A.M. and E.A. Dyl, 2005, "Market Structure and Trading Volume," Journal of Financial Research $28,115-131$.

Anderson, A.M. and E.A. Dyl, 2007, “Trading Volume: NASDAQ and the NYSE," Financial Analyst Journal 63, 79-86.

Atkins, A.B. and E.A. Dyl, 1997, "Market Structure and Reported Trading Volume: NASDAQ versus the NYSE,” Journal of Financial Research 20, 291-304.

Barber, B. and T. Odean, 2000, "Trading is Hazardous to Your Wealth: The Common Stock Investment Performance of Individual Investors,” Journal of Finance 55, 773-806.

Barber, B. and T. Odean, 2001, "Boys Will Be Boys: Gender Overconfidence and Common Stock Investment," Quarterly Journal of Economics 116, 261-292.

Barber, B. and T. Odean, 2002, “Online Investors: Do the Slow Die First?” Review of Financial Studies 15, 455-487.

Barber, B., T. Odean, and N. Zhu, 2009, “Do Retail Trades Move Markets?” Review of Financial Studies 22, 151-186.

Barberis, N., A. Shleifer, and R. Vishny, 1998, “A Model of Investor Sentiment,” Journal of Financial Economics 49, 307-343.

Berk, J.B., R.C. Green, and V. Naik, 1999, “Optimal Investment, Growth Options, and Security Returns," Journal of Finance 54, 1553-1607.

Brown, P.R., N. Chappel, R.D.S. Rosa, and T.S. Walter, 2006, "The Reach of the Disposition Effect: Large Sample Evidence across Investor Classes," International Review of Finance 1-2, 43-78.

Chan, L.K.C., N. Jegadeesh, and J. Lakonishok, 1996, “Momentum Strategies,” Journal of Finance 51, 1681-1713.

Chen, J. and H. Hong, 2002, "Discussion of Momentum and Autocorrelation in Stock Returns," Review of Financial Studies 15, 565-573.

Chordia, T. and L. Shivakumar, 2002, "Momentum, Business Cycle, and Time-Varying Expected Returns," Journal of Finance 57, 985-1019.

Cici, G., 2005, “The Relation of the Disposition Effect to Mutual Funds Trades and Performance," SSRN Working Paper.

Cochrane, J.H., 1996, “A Cross-Sectional Test of an Investment-Based Asset Pricing Model,” Journal of Political Economy 104, 572-621. 
Cohen, R.B., P.A. Gompers, and T. Vuolteenaho, 2002, "Who Underreacts to Cash-Flow News? Evidence from Trading between Individuals and Institutions," Journal of Financial Economics 66, 409-462.

Conrad, J.S. and G. Kaul, 1998, "An Anatomy of Trading Strategies," Review of Financial Studies 11, 489-519.

Coval, J. and T. Shumway, 2005, “Do Behavioral Biases Affect Prices?” Journal of Finance 60, 1-34.

Daniel, K., D. Hirshleifer, and A. Subrahmanyam, 1998, "Investor Psychology and Security Market Underand Over-reactions," Journal of Finance 53, 1839-1886.

D'Avolio, G., 2002, “The Market for Borrowing Stock,” Journal of Financial Economics 66, 271-306.

DeLong, B., L. Summers, A. Shleifer, and R. Waldmann, 1990, "Positive Feedback Investment Strategies and Destabilizing Rational Speculation," Journal of Finance 45, 379-395.

Dennis, P.J. and D. Strickland, 2002, “Who Blinks in Volatile Markets, Individuals or Institutions?” Journal of Finance 57, 1923-1949.

Dhar, R. and Z.N. Zhou, 2006, "Up Close and Personal: An Individual Level Analysis of the Disposition Effect," Management Science 52, 726-740.

Falkenstein, E.G., 1996, "Preferences for Stock Characteristics as Revealed by Mutual Fund Portfolio Holdings," Journal of Finance 51, 111-135.

Fama, E.F., 1998, "Market Efficiency, Long-Term Returns, and Behavioral Finance," Journal of Financial Economics 49, 283-306.

Fama, E.F. and K.R. French, 1996, "Multifactor Explanations of Asset Pricing Anomalies," Journal of Finance 51, 55-84.

Fama, E.F. and K.R. French, 2008, “Dissecting Anomalies,” Journal of Finance 63, 1653-1678.

Fama, E.F. and J. MacBeth, 1973, "Risk, Return, and Equilibrium: Empirical Tests," Journal of Political Economy 81, 607-636.

Frazzini, A., 2006, "The Disposition Effect and Under-Reaction to News," Journal of Finance 61, 20172046.

Goetzmann, W. and M. Massa, 2008, "Disposition Matters: Volume, Volatility, and Price Impact of a Behavioral Bias," Journal of Portfolio Management 34, 103-125.

Gompers, P. and A. Metrick, 2001, "Institutional Investors and Equity Prices," Quarterly Journal of Economics 116, 229-260.

Grinblatt, M. and B. Han, 2005, "Prospect Theory, Mental Accounting, and Momentum," Journal of Financial Economics 78, 311-339.

Grinblatt, M. and M. Keloharju, 2001, “What Makes Investors Trade?” Journal of Finance 56, 589-616.

Grinblatt, M., S. Titman, and R. Wermers, 1995, "Momentum Investment Strategies, Portfolio Performance, and Herding: A Study of Mutual Fund Behavior," American Economic Review 85, 1088-1105.

Grundy, B.F. and S.R. Martin, 2001, "Understanding the Nature of the Risks and the Source of the Rewards to Momentum Investing," Review of Financial Studies 14, 29-79.

Gutierrez, R. and E. Kelly, 2008, “The Long-Lasting Momentum in Weekly Returns,” Journal of Finance $63,415-447$.

Han, B. and A. Kumar, 2009, "Speculation, Realization Utility, and Volatility-Induced Retail Habitat," SSRN Working Paper. 
Haugen, R.A. and N.L. Baker, 1996, "Commonality in the Determinants of Expected Stock Returns," Journal of Financial Economics 41, 401-439.

Hong, H., T. Lim, and J.C. Stein, 2000, "Bad News Travels Slowly: Size, Analyst Coverage, and the Profitability of Momentum Strategies," Journal of Finance 55, 265-295.

Hong, H. and J.C. Stein, 1999, “A Unified Theory of Under-reaction, Momentum Trading, and Overreaction in Asset Markets," Journal of Finance 54, 2143-2184.

Hvidkjaer, S., 2008, "Small Trades and the Cross-Section of Stock Returns," Review of Financial Studies 21, 1123-1151.

Jegadeesh, N., 1990, "Evidence of Predictable Behavior of Security Returns," Journal of Finance 45, 881-898.

Jegadeesh, N. and S. Titman, 1993, "Returns to Buying Winners and Selling Losers: Implications for Stock Market Efficiency," Journal of Finance 48, 65-91.

Jegadeesh, N. and S. Titman, 2001, "Profitability of Momentum Strategies: An Examination of Alternative Explanations," Journal of Finance 56, 699-720.

Jegadeesh, N. and S. Titman, 2005, "Momentum," in R.M. Thaler, Ed. Advances in Behavioral Finance, Vol. 2, Princeton, NJ, Princeton University Press.

Johnson, T.C., 2002, "Rational Momentum Effects,” Journal of Finance 57, 585-608.

Kahneman, D. and A. Tversky, 1979, "Prospect Theory: An Analysis of Decision under Risk," Econometrica 47, 263-291.

Kumar, A., 2009, "Hard-to-Value Stocks, Behavioral Biases, and Informed Trading," Journal of Financial and Quantitative Analysis 44, 1375-1401.

Lee, C.M.C., 1992, "Earnings News and Small Traders," Journal of Accounting and Economics 15, 265302.

Lehmann, B.N., 1990, "Fads, Martingales, and Market Efficiency," Quarterly Journal of Economics 105, 1-28.

Lewellen, J., 2002, "Momentum and Autocorrelation in Stock Returns," Review of Financial Studies 15, $533-563$

Liu, L.X. and L. Zhang, 2008, "Momentum Profits, Factor Pricing, and Macroeconomic Risk," Review of Financial Studies 21, 2417-2448.

Lo, A.W. and A.C. MacKinlay, 1990, "When are Contrarian Profits Due to Stock Market Overreaction?" Review of Financial Studies 3, 175-205.

Locke, P. and S. Mann, 2004, "Professional Trader Discipline and Trade Disposition," Journal of Financial Economics 76, 401-444.

Malmendier, U. and D. Shanthikumar, 2007, “Are Small Investors Naïve about Incentives?” Journal of Financial Economics 85, 457-489.

Mitchell, M.L. and E. Stafford, 2000, "Managerial Decisions and Long-Term Stock Price Performance," Journal of Business 73, 287-329.

Nagel, S., 2005, “Short Sales, Institutional Investors, and the Cross-Section of Stock Return," Journal of Financial Economics 78, 277-309.

Newey, W.K. and K.D. West, 1987, “A Simple, Positive Semi-Definite, Heteroskedasticity, and Autocorrelation Consistent Covariance Matrix," Econometrica 55, 703-708. 
Nofsinger, J.R. and R.W. Sias, 1999, "Herding and Feedback Trading by Institutional Investors," Journal of Finance 54, 2263-2316.

Odean, T., 1998, “Are Investors Reluctant to Realize Their Losses?” Journal of Finance 53, 1775-1798.

Odean, T., 1999, “Do Investors Trade Too Much?” American Economic Review 89, 1279-1298.

Rouwenhorst, K.G., 1998, “International Momentum Strategies,” Journal of Finance 53, 267-284.

Shapira, Z. and I. Venezia, 2001, "Patterns of Behavior of Professionally Managed and Independent Investors," Journal of Banking and Finance 25, 1573-1587.

Shefrin, H. and M. Statman, 1985, "The Disposition to Sell Winners Too Early and Ride Losers Too Long: Theory and Evidence," Journal of Finance 40, 777-790.

Sias R., L. Starks, and S. Titman, 2006, "Changes in Institutional Ownership and Stock Returns: Assessment and Methodology," Journal of Business 79, 2869-2910.

Thaler, R., 1980, "Toward a Positive Theory of Consumer Choice," Journal of Economic Behavior and Organization 1, 39-60.

Wermers, R., 1999, "Mutual Fund Trading and the Impact on Stock Prices," Journal of Finance 54, 581-622.

Wermers, R., 2003, “Is Money Really “Smart?” New Evidence on the Relation between Mutual Fund Flows, Manager Behavior, and Performance Persistence," University of Maryland Working Paper.

Xu, Z., 2007, "Selling Winners, Holding Losers: Effect on Mutual Fund Performance and Flows," Virginia Tech Ph.D. Dissertation.

Yan, X.S. and Z. Zhang, 2009, "Institutional Investors and Equity Returns: Are Short-Term Institutions Better Informed?" Review of Financial Studies 22, 893-924. 